\title{
Long-term cost effectiveness of ticagrelor in patients with acute coronary syndromes in Thailand
}

\author{
Sukit Yamwong ${ }^{1}$, Unchalee Permsuwan ${ }^{2 *}$, Sirana Tinmanee ${ }^{3}$ and Piyamitr Sritara ${ }^{1}$
}

\begin{abstract}
Objectives: To evaluate the long-term cost-effectiveness of ticagrelor and ASA versus generic and branded clopidogrel and ASA in patients with ACS based on a Thai cost database.

Methods: A one-year decision tree and a long-term Markov model were constructed to estimate lifetime costs and quality-adjusted life years (QALYs). For the first year, data from PLATO (NCT00391872) were used to estimate the rate of cardiovascular events, resource use, and QALYs. For year 2 onwards, clinical effectiveness was estimated conditional on individual health states that occurred during the first year.

Results: In the base-case analysis, the incremental cost-effectiveness ratio (ICER) with ticagrelor was 292,504 $(\$ 9,476)$ and $60,055(\$ 1,946)$ THB $(\$) / Q A L Y$ compared with generic and branded clopidogrel, respectively. The probability of ticagrelor being cost-effective was above 99\% at a threshold of 160,000 THB/QALY compared with branded clopidogrel.

Conclusions: This health economic analysis provides cost effectiveness data for ticagrelor compared with both generic and branded clopidogrel in Thailand. Based on this analysis, it appears that ticagrelor is an economically valuable treatment for ACS compared with branded clopidogrel within the Thai context.
\end{abstract}

Keywords: Cost-effectiveness; Ticagrelor; Acute coronary syndrome; Clopidogrel

\section{Background}

Acute coronary syndrome (ACS) is a common cardiovascular disease associated with high complication and mortality rates. From the Thai ACS Registry - a survey conducted at 17 tertiary care centers in 2007 - the inhospital mortality rate was $12.6 \%$ [1]. A later survey in 2012 showed a lower rate of in-hospital mortality (4.8\%) but the mortality rate at one-year had not decreased (17.7\%) [2]. Moreover, a study of ACS patients under the Universal Coverage (UC) scheme and Civil Servant Medical Benefits Scheme (CSMBS) at all levels of hospital found that the in-hospital mortality rate was approximately $14 \%$, and that ACS was associated with substantial health care use and costs [3,4]. Various anti-platelet drugs have been proven to reduce cardiovascular events in ACS patients. Currently, there are several classes of anti-platelet

\footnotetext{
* Correspondence: unchalee.permsuwan@gmail.com

${ }^{2}$ Department of Pharmaceutical Care, Faculty of Pharmacy, Chiang Mai

University, Chiang Mai 50200, Thailand

Full list of author information is available at the end of the article
}

drugs available on the market including aspirin (ASA), thienopyridine products such as clopidogrel or prasugrel, and a new chemical class, the cyclopentyltriazolopyrimidines, which includes the direct-acting oral antagonist of the adenosine diphosphate $\mathrm{P}_{2} \mathrm{Y}_{12}$ receptor ticagrelor.

According to the 2012 American College of Cardiology/ American Heart Association guidelines, combined treatment with ASA plus a P2Y 12 inhibitor such as clopidogrel, prasugrel or ticagrelor is recommended as standard antiplatelet treatment in ACS [5]. However, clopidogrel is a pro-drug requiring transformation to an active metabolite, which results in a slower onset and less consistent inhibition of platelet aggregation compared with ticagrelor [6]. Ticagrelor represents a new treatment option for ACS. The PLATelet inhibition and patient Outcomes (PLATO) study was conducted to determine whether ticagrelor is superior to clopidogrel for the prevention of vascular events and death in a broad population of patients presenting with an ACS [7]. Thailand was a part of this 
multi-centre study. In the PLATO study, compared to clopidogrel in combination with ASA, ticagrelor in combination with ASA demonstrated superior efficacy in the prevention of thrombotic events for the composite endpoint of vascular death, myocardial infarction (MI), or stroke $(9.8 \%$ vs $11.7 \%$, hazard ratio $[\mathrm{HR}]=0.84 ; 95 \% \mathrm{CI}$ 0.77 to $0.92 ; \mathrm{p}<0.001)$. Trial-defined major bleeding events were similar in both treatment groups, but there were statistically significantly more combined major and minor bleeding events in the ticagrelor arm compared with the clopidogrel arm $(16.1 \%$ vs $14.6 \%, \mathrm{HR}=1.11$; $95 \%$ CI 1.03 to $1.30 ; \mathrm{p}=0.008$ ) and more non-coronary artery bypass grafting (non-CABG) related major bleeding events $(4.5 \%$ vs $3.8 \%, H R=1.19 ; 95 \%$ CI 1.02 to 1.38; $\mathrm{p}=0.03)$.

Treatment of ACS imposes a substantial burden on Thai society as a whole. When a new treatment becomes available, especially one with a higher cost but greater benefit than usual care, it is necessary to critically appraise the cost-effectiveness of this new treatment to determine whether the improvement in treatment efficacy makes financial sense, especially in the era of limited healthcare resources. Therefore, this study aimed to evaluate the longterm cost-effectiveness of ticagrelor and ASA versus clopidogrel and ASA in ACS patients in Thailand.

\section{Methods}

A two-part construct model with a one-year decision tree and a Markov model developed by Nikolic et al. [8] was used to compare ticagrelor with generic and branded clopidogrel. The model was designed to capture shortand long-term costs and outcomes. The clinical effectiveness data were obtained from the PLATO trial [7] while cost data were derived from a Thai database. All costs and effects were discounted at 3\% per annum as indicated by Thai guidelines [9]. Costs were presented in the year 2013 and effectiveness was measured in terms of quality adjusted-life years (QALYs). The health care payer perspective was undertaken.

\section{The decision model}

To model the short-term cost-effectiveness of ticagrelor, a one-year decision tree covering four mutually exclusive health states (no further event, non-fatal MI, non-fatal stroke, and death from any cause) was constructed as shown in Figure 1. During this phase, each ACS patient received clopidogrel $75 \mathrm{mg}$ once daily plus ASA 75$100 \mathrm{mg}$ or ticagrelor $90 \mathrm{mg}$ twice daily plus ASA 75$100 \mathrm{mg}$ for 12 months. We assumed the treatment duration lasted only one year and that there was no rebound effect for treatment remaining in the Markov cycles. At the end of one year, patients were allocated to one of the six mutually exclusive health states in the Markov model: no further event, non-fatal MI, post MI, non-fatal stroke, post stroke and dead (Figure 1). The non-fatal MI and non-fatal stroke health states were tunnel states allowing for a worse prognosis for patients in the year in which a non-fatal event occurred

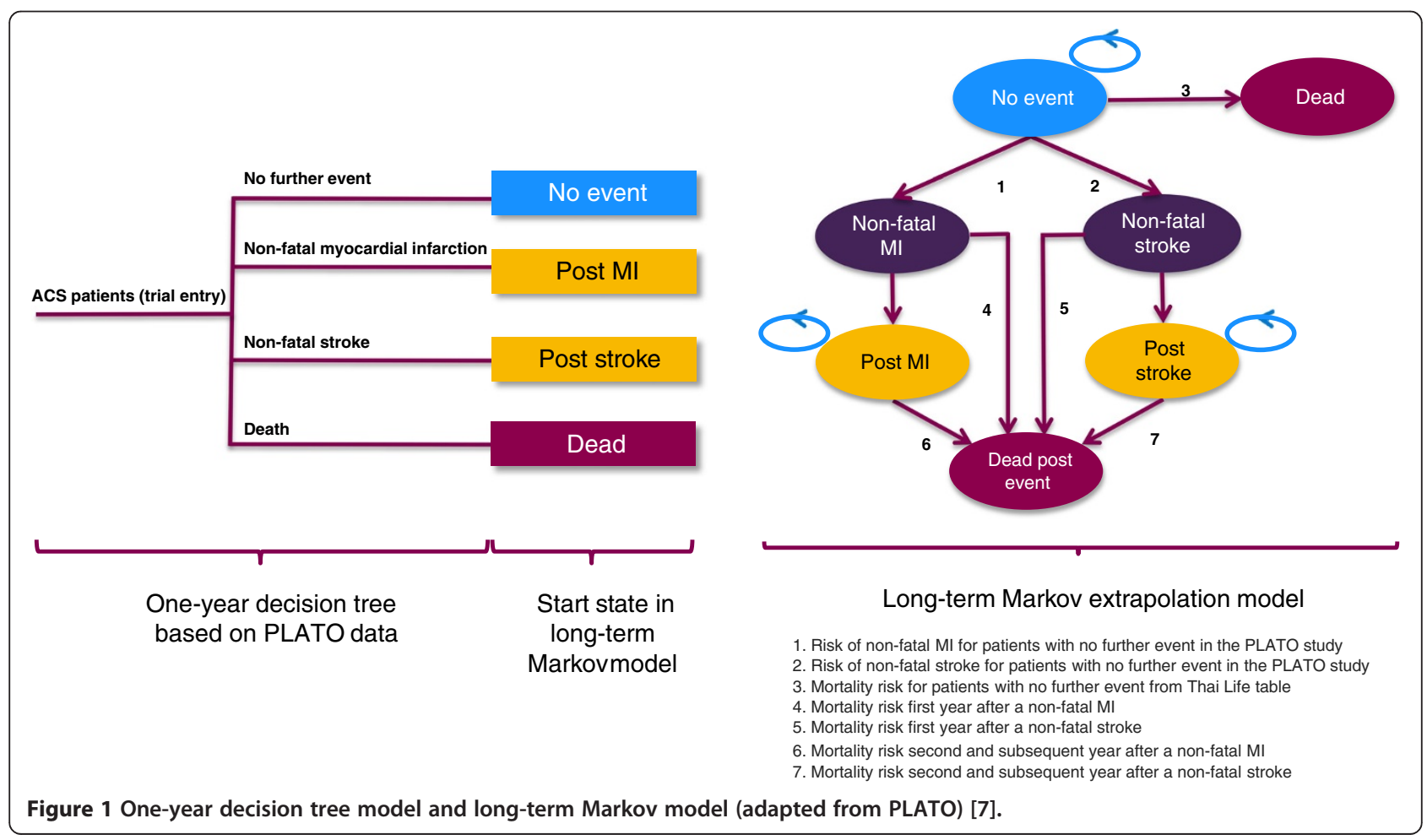


compared to a subsequent year. Patients in the post-MI or post-stroke states would remain in those states for all succeeding cycles until they moved to death state. The cycle length was one year with a lifetime horizon. We assumed our Thai cohort of ACS patients had a median age of 62 years (based on PLATO data [7] and consistent with the average age of ACS patients in the Thai Registry report [2]) and had similar percentages of ST segment elevation myocardial infarction (STEMI), non-ST segment elevation myocardial infarction (NSTEMI), and unstable angina (UA) as patients enrolled in the PLATO trial (Table 1) [7].

\section{Effectiveness parameters}

For a one-year decision tree, the effectiveness data were derived exclusively from the PLATO trial [7], as Thailand was included in this multi-centre study. A parametric time-to-event survival model with a Weibull distribution was employed in order to determine the baseline risk of events with clopidogrel treatment and a hazard ratio (HR) of ticagrelor treatment effect. Hence, the ticagrelor event rates were the product of baseline risk and a ticagrelor $\mathrm{HR}$ (Table 2).

Due to patients no longer being on study medications after one year according to our assumption, the identical transition probabilities for the second year onwards were

Table 1 Baseline characteristics of patients in the PLATO study, by treatment group* [7]

\begin{tabular}{|c|c|c|}
\hline Characteristic & $\begin{array}{l}\text { Ticagrelor group } \\
(\mathrm{N}=9333)\end{array}$ & $\begin{array}{l}\text { Clopidogrel group } \\
(\mathrm{N}=9291)\end{array}$ \\
\hline Age — median (range) & $62.0(19-97)$ & $62.0(21-94)$ \\
\hline Female sex — no. (\%) & $2655(28.4)$ & $2633(28.3)$ \\
\hline BMI — median (range) & $27(13-68)$ & $27(13-70)$ \\
\hline \multicolumn{3}{|l|}{$\begin{array}{l}\text { Cardiovascular risk factor - } \\
\text { no./total no. (\%) }\end{array}$} \\
\hline Habitual smoker & $3360(36.0)$ & $3318(35.7)$ \\
\hline Hypertension & $6139(65.8)$ & $6044(65.1)$ \\
\hline Dyslipidemia & $4347(46.6)$ & $4342(46.7)$ \\
\hline Diabetes mellitus & $2326(24.9)$ & $2336(25.1)$ \\
\hline \multicolumn{3}{|l|}{$\begin{array}{l}\text { Other medical history - } \\
\text { no./total no. (\%) }\end{array}$} \\
\hline $\mathrm{Ml}$ & 1900 (20.4) & $1924(20.7)$ \\
\hline $\begin{array}{l}\text { Percutaneous coronary } \\
\text { intervention }\end{array}$ & $1272(13.6)$ & $1220(13.1)$ \\
\hline Congestive heart failure & $513(5.5)$ & $537(5.8)$ \\
\hline \multicolumn{3}{|l|}{$\begin{array}{l}\text { Final diagnosis of ACS - } \\
\text { no./total no. (\%) }\end{array}$} \\
\hline ST-elevation Ml & $3496(37.5)$ & $3530(38.0)$ \\
\hline Non-ST-elevation MI & 4005 (42.9) & $3950(42.5)$ \\
\hline Unstable angina & 1549 (16.6) & $1563(16.8)$ \\
\hline $\begin{array}{l}\text { Other diagnosis or missing } \\
\text { data }\end{array}$ & $283(3.0)$ & $248(2.7)$ \\
\hline
\end{tabular}

*Adapted from PLATO [7].
Table 2 Input parameters and values used in the economic model

\begin{tabular}{|c|c|c|}
\hline Input parameters & Value & Source \\
\hline \multicolumn{3}{|l|}{ One-year decision tree } \\
\hline \multicolumn{3}{|l|}{ Ticagrelor } \\
\hline No event & 0.894 & PLATO [7], Nikolic [8] \\
\hline Non-fatal Ml & 0.050 & PLATO [7], Nikolic [8] \\
\hline Non-fatal stroke & 0.010 & PLATO [7], Nikolic [8] \\
\hline Death any cause & 0.046 & PLATO [7], Nikolic [8] \\
\hline \multicolumn{3}{|l|}{ Clopidogrel } \\
\hline No event & 0.875 & PLATO [7], Nikolic [8] \\
\hline Non-fatal Ml & 0.057 & PLATO [7], Nikolic [8] \\
\hline Non-fatal stroke & 0.009 & PLATO [7], Nikolic [8] \\
\hline Death any cause & 0.059 & PLATO [7], Nikolic [8] \\
\hline \multicolumn{3}{|l|}{ Markov model $^{a}$} \\
\hline $\begin{array}{l}\text { Annual risk of } \mathrm{Ml} \text { in the no } \\
\text { event state }\end{array}$ & 0.019 & PLATO [7], Nikolic [8] \\
\hline $\begin{array}{l}\text { Annual risk of stroke in the } \\
\text { no event state }\end{array}$ & 0.003 & PLATO [7], Nikolic [8] \\
\hline Risk of death in no event state ${ }^{b}$ & 2.000 & $\begin{array}{l}\text { Thai Life table [10], } \\
\text { Allen [11], Taneja [12] }\end{array}$ \\
\hline $\begin{array}{l}\text { Risk of death in the non-fatal } \\
\text { Ml state }^{b}\end{array}$ & 6.000 & PLATO [7], Nikolic [8] \\
\hline Risk of death in the post MI state ${ }^{b}$ & 3.000 & PLATO [7], Nikolic [8] \\
\hline $\begin{array}{l}\text { Risk of death in the non-fatal } \\
\text { stroke state }^{b}\end{array}$ & 7.430 & Dennis [13], Hanke [14] \\
\hline $\begin{array}{l}\text { Risk of death in the post stroke } \\
\text { state }\end{array}$ & 3.000 & PLATO [7], Nikolic [8] \\
\hline
\end{tabular}

${ }^{a}$ The values in the Markov model are the same for ticagelor and clopidgrel.

${ }^{b}$ Hazard ratio over standard mortality.

employed in both treatment strategies in the Markov model. The difference in both groups occurred for the proportion of patients in the different start states in the Markov model. The transition probabilities from no event to non-fatal MI or non-fatal stroke in the Markov model were estimated with an extrapolation of the observed HRs in the clopidogrel arm of PLATO beyond 1 year $[7,8]$. The annual mortality rate (MR) in the noevent state was estimated using age- and gender-specific MR from Thai lifetables [10]. To incorporate an increased risk of mortality associated with ACS, a HR was applied to the age- and gender-specific MR of the Thai population. Patients suffering an ACS event have a relatively high risk of a fatal event occurring within one year and the risk declines over time the longer that patients survive without a subsequent ACS event [11,12]; hence, the risk of death for patients in the no-event state was double that of standard mortality risk from Thai lifetables. The mortality risks of non-fatal MI, post-MI, and post-stroke were estimated by extrapolation of PLATO trial data [7]. The mortality risks of non-fatal stroke were derived from the literature $[13,14]$. 
QALY is the product of utility and life-years gained. Utilities within the one-year decision tree were based on EQ-5D data collected within the PLATO study $[7,8]$. In the Markov model, the baseline utility of the no-event state was also derived from the PLATO trial $[7,8]$. A decrement due to each health state was applied based on a previous study conducted in Thailand [15] (Table 3).

\section{Resource and cost parameters}

This study was carried out from the viewpoint of the payer; hence, only direct medical costs were taken into consideration. These included study medication, concomitant medications, hospitalizations, investigations, interventions, and bleeding-related resources. For the one-year decision tree, healthcare costs incurred in each treatment arm were based on resource used data from the PLATO trial $[7,8]$ and unit costs of those resources from data in Thailand (Additional file 1: TableS1) [16,17]. The cost of ticagrelor used was based on the manufacturer's price (94.16 THB per day). Clopidogrel costs were derived from the Drug and Medical Supply Information Center (DMSIC) in Thailand (branded $=72.53$ THB per day and the cheapest generic $=0.94 \mathrm{THB}$ per day) [18]. The drug costs included 7\% VAT. For year 2 onwards, the individual total cost of each health state was exclusively based on data from Thailand [4,15]. All costs were

\section{Table 3 Base-case utility values}

\begin{tabular}{|c|c|c|}
\hline Parameters & Value & Sources \\
\hline \multicolumn{3}{|l|}{ One-year decision tree } \\
\hline \multicolumn{3}{|l|}{ Ticagrelor } \\
\hline No event & 0.873 & PLATO [7], Nikolic [8] \\
\hline Non-fatal Ml & 0.811 & PLATO [7], Nikolic [8] \\
\hline Non-fatal stroke & 0.735 & PLATO [7], Nikolic [8] \\
\hline Death any cause & 0.247 & PLATO [7], Nikolic [8] \\
\hline \multicolumn{3}{|l|}{ Clopidogrel } \\
\hline No event & 0.876 & PLATO [7], Nikolic [8] \\
\hline Non-fatal Ml & 0.814 & PLATO [7], Nikolic [8] \\
\hline Non-fatal stroke & 0.738 & PLATO [7], Nikolic [8] \\
\hline Death any cause & 0.250 & PLATO [7], Nikolic [8] \\
\hline \multicolumn{3}{|l|}{ Markov model $^{a}$} \\
\hline $\begin{array}{l}\text { No event aged less than } \\
70 \text { years }\end{array}$ & 0.875 & PLATO [7], Nikolic [8] \\
\hline No event aged $70-79$ years & 0.843 & PLATO [7], Nikolic [8] \\
\hline No event aged over 79 years & 0.781 & PLATO [7], Nikolic [8] \\
\hline $\begin{array}{l}\text { Annual utility decrement Ml } \\
1^{\text {st }} \text { year Markov model and } \\
2^{\text {nd }} \text { year onward }\end{array}$ & 0.147 & Tamteeranon [15] \\
\hline $\begin{array}{l}\text { Annual utility decrement stroke } \\
1^{\text {st }} \text { year Markov model and } \\
2^{\text {nd }} \text { year onward }\end{array}$ & 0.226 & Tamteeranon [15] \\
\hline
\end{tabular}

adjusted to the year 2013 using the consumer price index (medical care component) [19]. Table 4 presents the total costs used in this study.

\section{Model analyses}

Costs and QALY were calculated over a lifetime horizon and presented as the incremental cost-effectiveness ratio (ICER) which was the ratio of an incremental cost and an incremental QALY. The model was constructed and run using Microsoft Excel version 2007.

\section{Sensitivity analyses}

A series of sensitivity analyses were carried out to address uncertainty of parameters in the model. One-way sensitivity analysis was conducted to assess the uncertainty surrounding each parameter individually. The variables tested in the one-way sensitivity analysis included all transition probabilities, utilities and cost parameters.

Table 4 Total costs used in the model ${ }^{\mathrm{a}}$

\begin{tabular}{|c|c|c|}
\hline Items & $\begin{array}{l}\text { Cost } \\
\text { (THB) }\end{array}$ & Sources \\
\hline \multicolumn{3}{|l|}{ One-year decision tree } \\
\hline \multicolumn{3}{|l|}{ Ticagrelor } \\
\hline Annual drug cost & 34,368 & Manufacturer's price \\
\hline No event & 117,404 & Nikolic [8], Riewpaiboon [16] \\
\hline Non-fatal Ml & 204,851 & $\begin{array}{l}\text { Nikolic [8], Riewpaiboon [16], } \\
\text { Central office for Healthcare } \\
\text { Information [17] }\end{array}$ \\
\hline Non-fatal stroke & 141,918 & Nikolic [8], Riewpaiboon [16] \\
\hline Death any cause & 120,132 & Nikolic [8], Riewpaiboon [16] \\
\hline \multicolumn{3}{|l|}{ Clopidogrel } \\
\hline $\begin{array}{l}\text { Annual drug cost } \\
\text { (branded price) }\end{array}$ & 26,473 & DMSIC [17] \\
\hline $\begin{array}{l}\text { Annual drug cost } \\
\text { (generic price) }\end{array}$ & 344 & DMSIC [17] \\
\hline No event & 120,307 & Nikolic [8], Riewpaiboon [16] \\
\hline Non-fatal Ml & 207,753 & $\begin{array}{l}\text { Nikolic [8], Riewpaiboon [16], } \\
\text { Central office for Healthcare } \\
\text { Information [17] }\end{array}$ \\
\hline Non-fatal stroke & 144,821 & Nikolic [8], Riewpaiboon [16] \\
\hline Death any cause & 123,034 & Nikolic [8], Riewpaiboon [16] \\
\hline \multicolumn{3}{|l|}{ Markov model } \\
\hline $\begin{array}{l}\text { Total cost Ml } 1^{\text {st }} \text { year } \\
\text { Markov model }\end{array}$ & 168,196 & Anukoolsawat [4] \\
\hline $\begin{array}{l}\text { Total cost Ml } 2^{\text {nd }} \text { year } \\
\text { and onward }\end{array}$ & 35,926 & Anukoolsawat [4] \\
\hline $\begin{array}{l}\text { Total cost stroke } 1^{\text {st }} \text { year } \\
\text { Markov model }\end{array}$ & 79,800 & Tamteeranon [15] \\
\hline $\begin{array}{l}\text { Total cost stroke } 2^{\text {nd }} \text { year } \\
\text { and onward }\end{array}$ & 12,642 & Tamteeranon [15] \\
\hline Total cost of no event & 21,866 & Anukoolsawat [4] \\
\hline
\end{tabular}

${ }^{a}$ Detailed table of Thai hospital charges and unit cost (Baht) for the resource use collected in the PLATO trial provided in the Additional file 1: Table S1. 
Transition probabilities were varied first by $\pm 20 \%$, and then by a reduction of $50 \%$ and an increase of $200 \%$. All cost parameters were varied by $20 \%$ except drug costs, the ticagrelor cost was varied by $10 \%$ while the cost of the least expensive generic clopidogrel was set at $10 \%$ lower than current prices, and the cost of branded clopidogrel was set at $10 \%$ higher than current price. The results were presented as a tornado diagram. Probabilistic sensitivity analysis (PSA) was also undertaken. With the assigned distribution to each model parameter, uncertainty was then propagated through the model using Monte Carlo Simulation with parameter values drawn at random. The decision analysis model was simulated on a thousand iterations. The PSA results of ticagrelor vs branded clopidogrel and ticagrelor vs generic clopidogrel were presented as cost-effectiveness acceptability curves. For the Thai context, an ICER of less than 160,000 THB/ QALY is considered cost effective [20]. This is consistent with WHO recommendations that an ICER of 1GDP per capita demonstrates acceptable cost-effectiveness, while an ICER of over 3GDP per capita is justified to be considered not cost-effective [21]. The GDP per capita in Thailand in 2013 was 174,658 THB [22,23].

\section{Results}

The results showed that, compared with either generic or branded clopidogrel, ticagrelor treatment had a higher total cost with higher QALY. However, the difference in cost was less marked in analyses using branded versus generic clopidogrel (6,553 vs 31,918 THB respectively) resulting in a lower ICER of branded clopidogrel than generic clopidogrel $(60,055$ vs 292,504 THB/QALY respectively) compared with ticagrelor (Table 5).

\section{Sensitivity analysis}

Of the 26 variables tested in one-way sensitivity analyses, we found that the cost of clopidogrel, the cost of the no-event state within the trial of both ticagrelor and clopidogrel, and the HR of standard mortality in the noevent state had the greatest impact on ICER (Figure 2).

Table 5 Base-case result

\begin{tabular}{|c|c|c|c|c|}
\hline & Ticagrelor & Clopidogrel & Incremental & ICER \\
\hline \multicolumn{5}{|c|}{ Ticagrelor vs generic clopidogrel } \\
\hline Costs (THB) & 368,747 & 336,829 & 31,918 & \\
\hline Life-years & 9.201 & 9.079 & 0.122 & 261,197 \\
\hline QALYS & 7.711 & 7.602 & 0.109 & 292,504 \\
\hline \multicolumn{5}{|c|}{ Ticagrelor vs branded clopidogrel } \\
\hline Costs (THB) & 368,747 & 362,194 & 6,553 & \\
\hline Life-years & 9.201 & 9.079 & 0.122 & 53,627 \\
\hline QALYS & 7.711 & 7.602 & 0.109 & 60,055 \\
\hline
\end{tabular}

Compared with branded clopidogrel, ticagrelor had more than $99 \%$ probability of being cost-effective within the predefined threshold of 160,000 THB/QALY. However, ticagrelor was less cost-effective compared with generic clopidogrel (Figure 3).

\section{Discussion}

We conducted a cost-effectiveness study using an analytical model to examine whether the new treatment, ticagrelor in combination with ASA, was cost-effective compared with either generic or branded clopidogrel in combination with ASA for treating ACS patients from a healthcare payer perspective. Our model was composed of a one-year decision tree and a Markov model to capture short- and long-term outcomes. We found that the price of clopidogrel had the greatest impact on ICER. Compared with generic clopidogrel (0.94 THB per day), ticagrelor had a cost per QALY gained of 292,504 THB which was greater than the threshold of 160,000 THB/ QALY. However, when branded clopidogrel was used as the comparator, ticagrelor treatment was cost-effective within the predefined threshold for Thailand.

This study is predicated on the assumption that generic clopidogrel is equally as efficacious and safe as the branded counterpart. However, Gomez et al. reported that most clopidogrel copies are not of equivalent quality [24]. A high number of impurities were found in many copies; over $60 \%$ of the generic copies contained more than four times the amount of hydrolysis product or R-enantiomer compared with branded clopidogrel. In addition, $50 \%$ of the samples did not comply with the 95-105\% limits for content. As a consequence, the results of ACS treatment with generic clopidogrel might not be the same as branded clopidogrel, especially in a very high-risk group, which would affect the conclusions of our analysis.

Several limitations of this study need to be mentioned. Firstly, the information on short-term resource use for the treatment of ACS was based on data from the PLATO trial [7], which was conducted in accordance with a strict protocol, and may not accurately reflect real practice in ACS management in Thailand. We reconciled this overestimated cost by using the unit cost item from Thai data.

Secondly, due to a paucity of data from Thailand, we estimated the cost of the no-event state in the Markov model from outpatient visit and investigation costs from the 1-year cost of MI reported in Anukoolsawat [4], but excluding inpatient and intervention costs. As a result, the no-event total cost was higher than the total cost of $2^{\text {nd }}$ year stroke in the Markov model. This limitation was due to the fact that available published reports on the cost of MI and stroke were based on data collected from two different centers, a medical school (for MI) and 


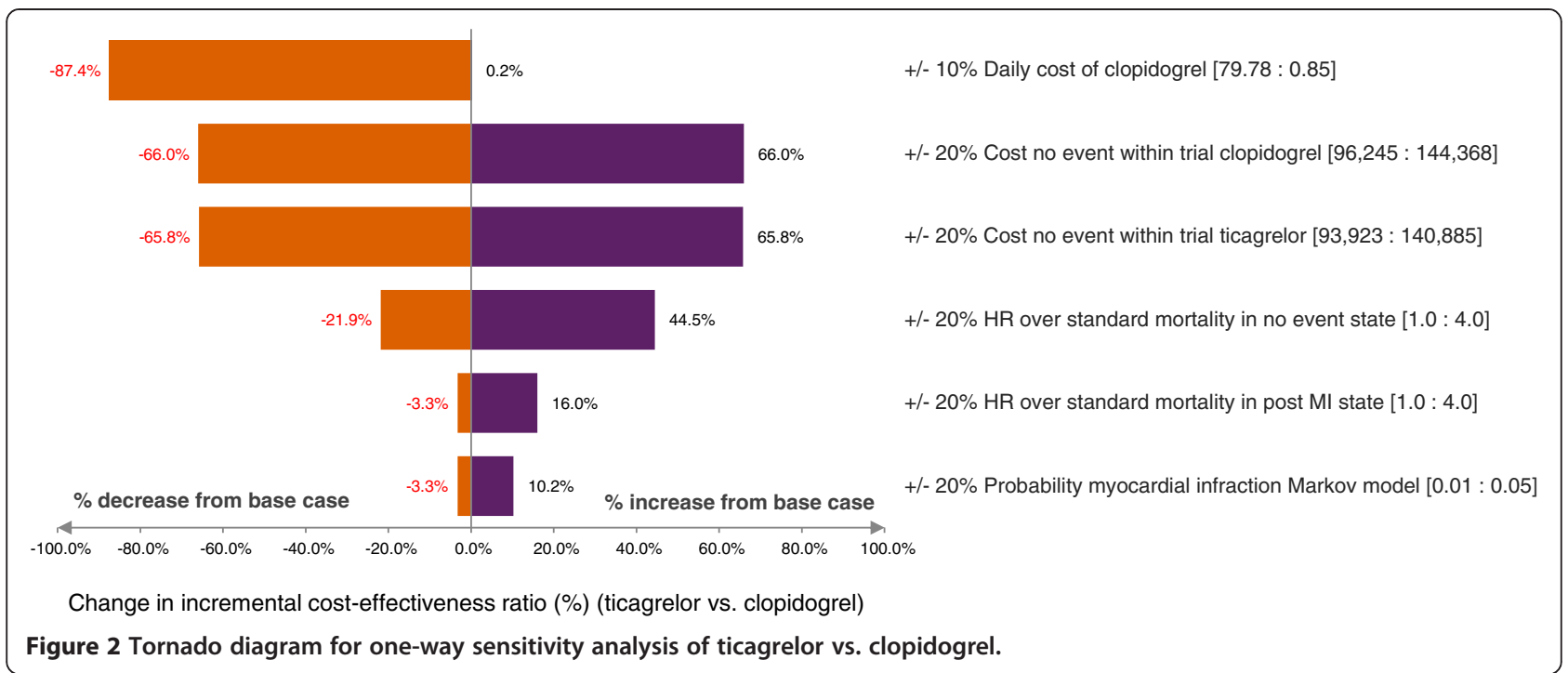

a government neurological institute (for stroke). The costs might not be comparable because of different treatment and resource use patterns at different centers. To address this, we tested the impact of stroke cost parameters on the model results in the sensitivity analyses. We varied the cost of stroke during the first year and from year 2 onwards in the Markov model by $100 \%$ and found that the ICER results were not sensitive to these two parameters.

A third limitation arises from the structure of the Markov model, which does not explicitly allow patients to suffer multiple cardiovascular events in their lifetime. Furthermore, this study is based on a payer perspective and limited only to direct medical costs. Direct nonmedical costs such as transportation or indirect costs such as lost productivity are not taken into consideration.
The finding from Anukoolsawat [4] reported that ACS was associated with a high economic burden for patients and their families resulting from loss of productivity, and that the indirect cost of ACS was even higher than the direct health care costs. Therefore, excluding these types of costs underestimates the true total cost of ACS to Thai society.

\section{Conclusions}

This health economic analysis supports the cost effectiveness of ticagrelor compared with branded clopidogrel in Thailand. The ICER of ticagrelor compared with branded clopidogrel is 60,055 THB/QALY. Therefore, ticagrelor appears to be an economically valuable treatment for ACS compared with branded clopidogrel within the Thai context.

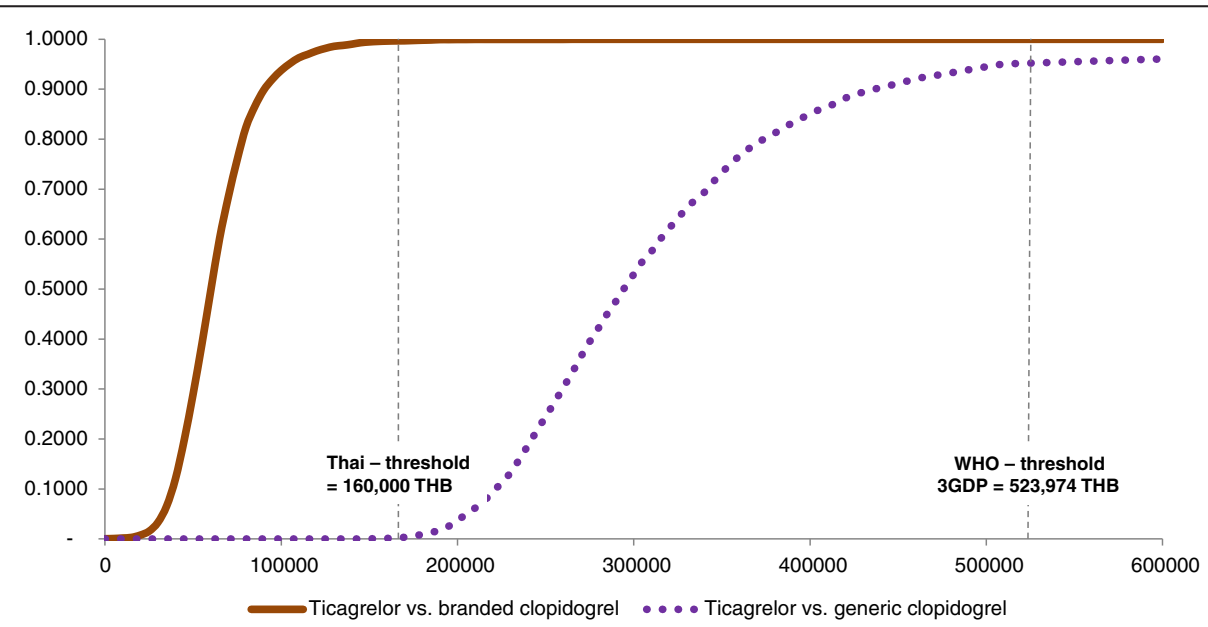

Figure 3 Cost-effectiveness acceptability curves. 


\section{Additional file}

Additional file 1: Table S1. Costs used in the model.

Competing interests

Sirana Tinmanee was a former employee of AstraZeneca (Thailand) Ltd.

\section{Authors' contributions}

YS, SP, TS and PU designed the study. YS and PU contributed to draft of the paper. All authors read and approved the final manuscript.

\section{Author details}

'Department of Medicine, Faculty of Medicine Ramathibodi Hospital, Mahidol University, Bangkok 10400, Thailand. 'Department of Pharmaceutical Care, Faculty of Pharmacy, Chiang Mai University, Chiang Mai 50200, Thailand. ${ }^{3}$ AstraZeneca (Thailand) Ltd, Bangkok 10120, Thailand.

Received: 14 January 2014 Accepted: 28 July 2014

Published online: 14 November 2014

\section{References}

1. Srimahachota S, Kanjanavanit R, Boonyaratavej S, Boonsom W, Veerakul G, Tresukosol D: Demographic, management practices and in-hospital outcomes of Thai Acute Coronary Syndrome Registry (TACSR): the difference from the Western World. J Med Assoc Thai 2007, 90(suppl 1):S1-S11.

2. Srimahachota $S$, Boonyaratavej $S$, Kanjanavanit $R$, Sritara $P$, Krittayaphong $R$, Kunjara-Na-Ayudhya R, Tatsanavivat P: Thai Registry in Acute Coronary Syndrome (TRACS)-an extension of Thai Acute Coronary Syndrome Registry (TACS) group: lower in-hospital but still high mortality at one-year. J Med Assoc Thai 2012, 95(4):508-518.

3. Prachuabmor C, Weerakul K, Kanchanawanich R: Thai Acute Coronary Syndrome Registry Report. Bangkok: Health Systems Research Institute; 2004

4. Anukoolsawat $P$, Sritara P, Teerawattananon Y: Costs of lifetime acute coronary syndrome treatment at Ramathibodi hospital. Thai Heart J 2006, 19:132-143.

5. Jneid $H$, Anderson $J L$, Wright RS, Adams CD, Bridges CR, Casey DE, Ettinger SM, Fesmire FM, Ganiats TG, Lincoff AM, Peterson ED, Philippides GJ, Theroux $\mathrm{P}$, Wenger NK, Zidar JP: ACCF/AHA focused update of the guideline for the management of patients with unstable angina/non -ST-elevation myocardial infarction. Circulation. 2012, 2012(14):875-910.

6. Storey RF, Husted S, Harrington RA, Heptinstall S, Wilcox RG, Peters G, Wickens M, Emanuelsson H, Gurbel P, Grande P, Cannon CP: Inhibition of platelet aggregation by AZD6140, a reversible oral P2Y12 receptor antagonist, compared with clopidogrel in patients with acute coronary syndromes. J Am Coll Cardiol 2007, 50:1852-1856.

7. Wallentin L, Becker RC, Budaj A, Cannon CP, Emanuelsson H, Held C, Horrow J, Husted S, James S, Katus H, Mahaffey KW, Scirica BM, Skene A, Steg PG, Storey RF, Harrington RA, PLATO Investigators, Freij A, Thorsén M: Ticagrelor versus clopidogrel in patients with acute coronary syndromes. N Engl J Med 2009, 361:1045-1057.

8. Nikolic E, Janzon M, Hauch O, Wallentin L, Henriksson M: Cost-effectiveness of treating acute coronary syndrome patients with ticagrelor for 12 months: results from the PLATO study. Eur Heart J 2013, 34:220-228.

9. Permsuwan U, Guntawongwan K, Buddhawongsa P: Handling time in economic evaluation studies. In Thai National Health Technology Assessment Guideline. Edited by Chaikledkaew U, Teerawattananon Y, Kong pitayachai S, Suksomboon N. Bangkok: Chulalongkorn University Press; 2009:161-185.

10. World Health Organization: Thai life table by country. 2009. http://www who.int/healthinfo/statistics/.

11. Allen LA, O'Donnell CJ, Camargo CA Jr, Giugliano RP, Lloyd-Jones DM: Comparison of long-term mortality across the spectrum of acute coronary syndromes. Am Heart J 2006, 151:1065-1071.

12. Taneja AK, Collinson J, Flather MD, Bakhai A, de Arenaza DP, Wang D, Adgey J, Fox KA: Mortality following non-ST elevation acute coronary syndrome: 4 years follow-up of the PRAIS UK Registry (Prospective Registry of Acute Ischaemic Syndromes in the UK). Eur Heart J 2004, 25:2013-2018.
13. Dennis MS, Burn JP, Sandercock PA, Bamford JM, Wade DT, Warlow CP: Long-term survival after first-ever stroke: the Oxfordshire Community Stroke Project. Stroke 1993, 24:796-800

14. Hankey GJ, Jamrozik K, Broadhurst RJ, Forbes S, Burvill PW, Anderson CS, Stewart-Wynne EG: Five year survival after first-ever stroke and related prognostic factors in the Perth Community Stroke Study. Stroke 2000, 31:2080-2086.

15. Tamteerano $Y$, Khonputsa $P$, Chaikledkaew U, Teerawattananon $Y$, Lim S: Economic evaluation of HMG-COA reductase inhibitors (statin) for primary prevention of cardiovascular diseases among Thai population. Bangkok: Graphico System; 2008.

16. Riewpaiboon A: Standard cost list for health technology assessment http://www.hitap.net/costingmenu.

17. Central office for Healthcare Information: $\mathrm{CHI}$ news and announcement http://www.chi.or.th/

18. Drug and Medical Supply Information Center: Prices of drugs and medical supply. http://dmsic.moph.go.th/price.htm.

19. Bureau of Trade and Economics Indices, Ministry of Commerce: CPI (Medical care). http://www.price.moc.go.th/price/cpi/index_new_e.asp.

20. The Health Intervention and Technology Assessment Program: Policy Brief. http://hitap.net.

21. World Health Organization: CHOosing Interventions that are Cost Effective (WHO-CHOICE). http://www.who.int/choice/costs/CER_thresholds/ en/index.html.

22. The World Bank: GDP per capita. http://data.worldbank.org/indicator/NY GDP.PCAP.CD.

23. National Economic and Social Development Board: Thai Economic Performance in Q3 and Outlook for 2013 and 2014. http://eng.nesdb.go.th/.

24. Gomez Y, Adams E, Hoogmartens J: Analysis of purity in 19 drug product tablets containing clopidogrel: 18 copies versus the original brand. J Pharm Biomed Anal 2004, 34:341-348.

\section{doi:10.1186/s13561-014-0017-3}

Cite this article as: Yamwong et al:: Long-term cost effectiveness of ticagrelor in patients with acute coronary syndromes in Thailand. Health Economics Review 2014 4:17

\section{Submit your manuscript to a SpringerOpen ${ }^{\odot}$ journal and benefit from:}

- Convenient online submission

- Rigorous peer review

- Immediate publication on acceptance

- Open access: articles freely available online

- High visibility within the field

- Retaining the copyright to your article

Submit your next manuscript at $>$ springeropen.com 